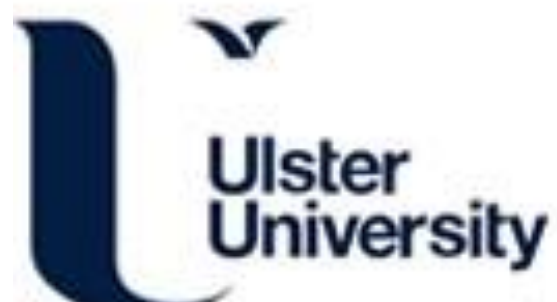

Cost-effective RSSI Wi-Fi Positioning Solution for Ambulatory Patient Monitoring Devices

Catherwood, P., Zech, T., \& McLaughlin, JAD. (2010). Cost-effective RSSI Wi-Fi Positioning Solution for Ambulatory Patient Monitoring Devices. In Unknown Host Publication (pp. 557-560). Loughborough University.

Link to publication record in Ulster University Research Portal

Published in:

Unknown Host Publication

Publication Status:

Published (in print/issue): 09/11/2010

\section{Document Version}

Author Accepted version

\section{General rights}

Copyright for the publications made accessible via Ulster University's Research Portal is retained by the author(s) and / or other copyright owners and it is a condition of accessing these publications that users recognise and abide by the legal requirements associated with these rights.

\section{Take down policy}

The Research Portal is Ulster University's institutional repository that provides access to Ulster's research outputs. Every effort has been made to ensure that content in the Research Portal does not infringe any person's rights, or applicable UK laws. If you discover content in the Research Portal that you believe breaches copyright or violates any law, please contact pure-support@ulster.ac.uk. 


\title{
Cost-effective RSSI Wi-Fi Positioning Solution for Ambulatory Patient Monitoring Devices
}

\author{
Philip A. Catherwood ${ }^{\# 1}$, Thomas Zech ${ }^{* 2}$, James McLaughlin ${ }^{\sim 3}$ \\ ${ }^{\# *}$ Nanotechnology and Integrated Bioengineering Centre (NIBEC), University of Ulster at Jordanstown, Newtownabbey,
}

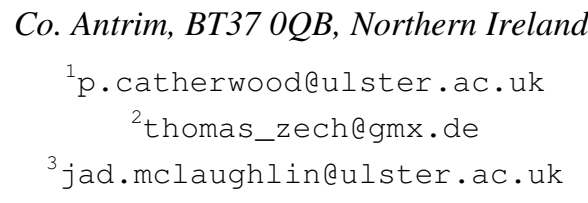

\begin{abstract}
This paper presents a novel patient location solution using an RSSI (Received Signal Strength Indicator) fingerprinting method, integrated into an ambulatory patient monitoring device. Results show that patients can be located in a pedestrian-rich environment to a typical accuracy of $2 \mathrm{~m}$ in realtime with only a basic training sequence for the system. In addition, coupled with accelerometer, ECG and respiration rate technology, medical staff can know exactly where a patient is located and what medical requirement to expect when they get there; e.g., requirement for defibrillation equipment, first aid due to a fall, etc. This offers a robust and dependable wireless system that increases patient safety and freedom, while allowing clinicians ability to meet patients' needs in a flexible way.
\end{abstract}

\section{INTRODUCTION}

Un-tethered patient monitors attract great interest in modern medicine [1] - [3] and location awareness is a major point of interest in many applications because of the growing proliferation of mobile devices. It affords patients \& doctors increased flexibility and reduces hospital resource utilisation. With an aging population burdening healthcare services [4], such systems will become essential tools in overall efficient healthcare operational strategies, with the sector predicted to be worth $\$ 7.2 \mathrm{bn}$ by 2015 [5]. These devices are often equipped with Wi-Fi modules, allowing them to be tracked and located in real-time.

Introduction of ambulatory patient monitors means patients are free to move around their local environment. However, this ultimately leads to situations where patients under care are unable to be located by medical staff in a timely manner when the ambulatory monitor indicates they require medical attention due to a cardiac, respiratory, etc, event. If a patient is having an episode, time for medical intervention is essential. Wi-Fi positioning in a hospital care environment allows immediate location of patients and thus ensures timely intervention. Many patients who are in hospital for the treatment of chronic illness are generally older and are more likely to be easily disorientated, become lost or may have memory impairments (e.g.: Alzheimer's disease), thus location is important for patient safety. It also allows clinicians to readily locate patients when meals are served or for medication administration.

There are a number of solutions to address the issue of patient tracking. These include RFID [6], GSM [7] and GPS
[8]. Each of these are stand-alone or additional devices. The solution being reported integrates existing devices and hospital Wi-Fi networks with a simple solution based on free software.

Engineering has developed patient monitors which allow patients to be mobile, but has created a new problem of patient location in an emergency. Hence, this work is both significant and timely as it employs established technology of Wi-Fi positioning and integrates it into emerging ambulatory medical devices in a cost effective value-added way to address the serious issue of patient location during a medical emergency.

This paper presents the development and trial of a novel cost effective solution to patient location based on Wi-Fi RSSI measurements within a two story building with an already established Wi-Fi network. Section II describes the measurements system utilised, the environment and the test procedure. Section III reports on the experimental results, Section IV highlights conclusions.

\section{MeAsurement System, EnVIRONMENT ANd PROCEDURE}

\section{A. System}

This system is based on the principles of RSSI monitoring to calculate position within a 3 -dimensional building space. This test system used five established Wi-Fi access points over two levels of a research building to prove and trial the technology. The signal propagation in 802.11 networks depends strongly on the environment. Building layout, construction materials and furnishings influence the signal propagation; since effects such as reflection or diffraction cause multipath fading in the received signal envelope. Preliminary signal attenuation measurements highlighted that there is no close correlation between the theoretical free space attenuation and the real signal attenuation if measured in an indoor environment due to the aforementioned effects, as reported by [9]. Thus, a site specific solution is required. While there are many options such as the Cell of Origin (COO) method, path loss model using triangulation, partition model and fingerprinting [10,11]. The choice of the fingerprinting approach is based on ease of development, low processing power and proposed accuracy. It also accounts for small and large scale fading within the building. However, it is acknowledged that fingerprinting 
incurs an off-line system training cost relative to the complexity of the environment.

The proposed positioning system was mainly developed in Matlab and consisted of several tools. An open source Wi-Fi scanner modified to enable the acquisition of RSSIfingerprints with respect to position was employed. Euclidean distance in signal space between the fingerprints and the currently measured RSSI values formed the basis of determining the current position. A radio map (database of RSSI-vectors) was generated by collecting RSSI-fingerprints at sample points within the desired area. Incoming network information such as RSSI, MAC and SSID were processed by a positioning algorithm. A site survey tool (developed in Matlab) was designed to collect and interpret the fingerprints in an easy way, since the phase of collecting all fingerprints can be time consuming if the desired area is large. A software tool for interpolating the radio map, based on k-Nearest Neighbour (k-NN) and Inverse Distance Weighting (IDW) (developed in Matlab), was developed to enable higher granularity of positions without collecting more fingerprints, thus saving considerable time and effort in the commissioning phase.

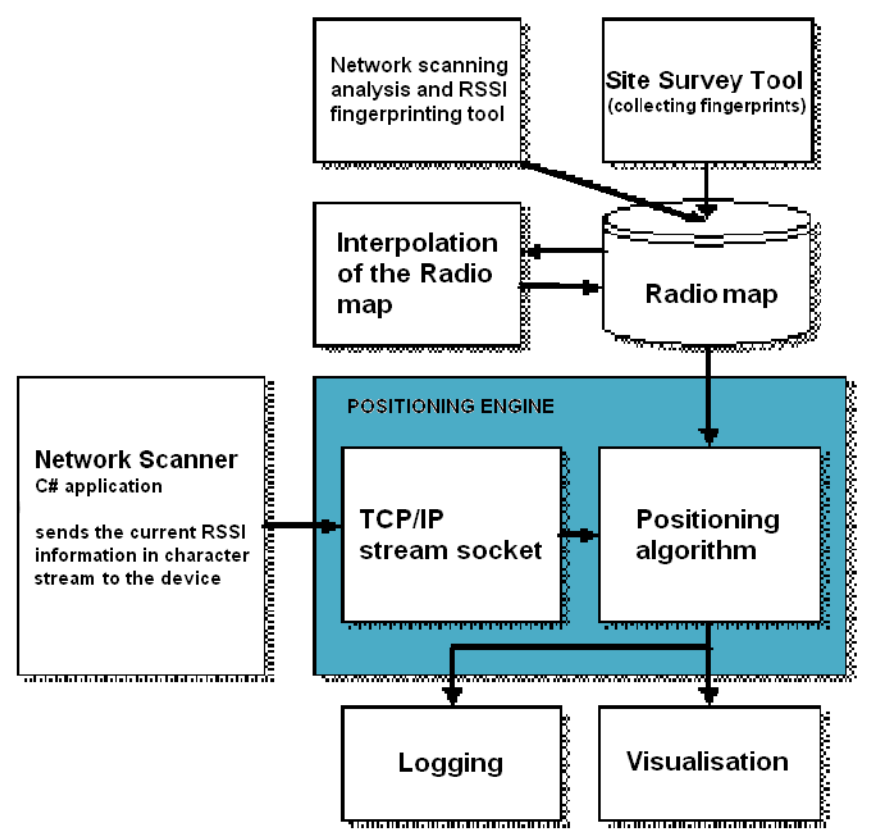

Fig. 1: Software design and integration model

A C\# console application was developed to interrogate the mobile device. This application will scan for networks at specified intervals and then send the actual measured RSSI values with the corresponding MAC addresses to the positioning application via a TCP/IP connection. When the algorithm has determined a position, it is visualised in the application-specific graphical user interface and all determined positions are logged with a time-stamp for subsequent investigations.

Generally, applying the solution to a real environment takes place in two stages. Firstly, in the calibration phase, Received
Signal Strength Indicator (RSSI) measurements from several access points are collected at specific reference points in the environment with a grid resolution of $0.5 \mathrm{~m}$. The radio map of the environment can be created using the site survey tool, performed by a site survey tour through the building while recording received RSSI-vectors; the route is then reproduced on the 3-dimensional grid to assign coordinates to the RSSI vectors. Secondly, in the on-line phase, a mobile device measures the RSSI values from all available Wi-Fi access points (AP) at a rate of $10 \mathrm{~Hz}$ and reports them to a central server that performs the positioning algorithm. The currently measured RSSI values are compared with the radio map to find the best matching fingerprint using the best-match algorithm, and thus assume the current position. It is also possible that the computation of the position can be performed on the mobile device; but this is often not desired due to higher performance requirements and increased energy consumption.

From an observation of the calibration phase at the position $i$ and an observation of the positioning phase, the Euclidean distance d can be calculated as follows:

$$
d=\sqrt{\left(S S_{c i 1}-S S_{p 1}\right)^{2}+\ldots+\left(S S_{c i n}-S S_{p n}\right)^{2}}
$$

where: $\mathrm{SS}_{\mathrm{cin}}$ is the signal strength of AP $\mathrm{n}$ at point $\mathrm{i}$ during the calibration phase, and $S_{\mathrm{pn}}$ is the signal strength of AP $n$ during the positioning phase.

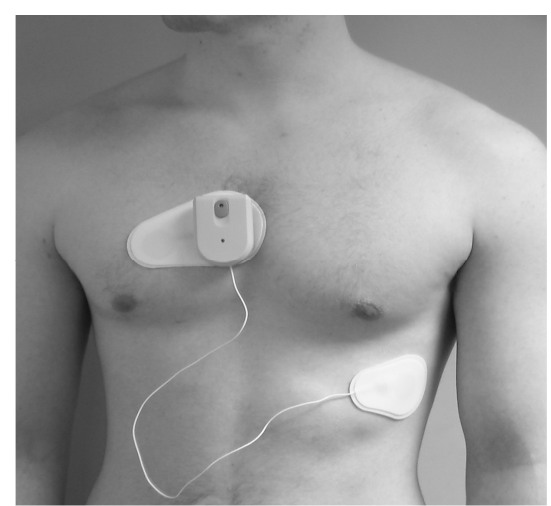

Fig. 2: Ambulatory patient monitoring device

\section{B. Environment}

To investigate the performance of the positioning system in a large indoor site, the ground floor (level A) and first floor (level B) of the modern NIBEC complex at University of Ulster, Jordanstown, has been used. The building is of metal frame construction. The previously established Wi-Fi network of the building was used for the experiment, containing five Linksys devices (model WAP54G) with launch power of $+15 \mathrm{dBm}$, all located on level B. The arrangement of the APs can be observed from the plan in figure 3. A number of locations within NIBEC were studied, but in particular, specific tests are reported for the kitchen $\left(25 \mathrm{~m}^{2}\right)$, boardroom $\left(30 \mathrm{~m}^{2}\right)$, laboratory $\left(80 \mathrm{~m}^{2}\right)$ and lecture room $\left(70 \mathrm{~m}^{2}\right)$. 


\section{The test procedure}

To evaluate the mobile positioning system, three performance tests were chosen to characterise the accuracy of the implemented solution; precision of the system to distinguish between two adjacent rooms on the same level; two adjacent rooms on different levels and finally measurement at random fixed locations. All experiments were carried out during office hours, where there was a steady flow of pedestrian traffic throughout the data collection process.

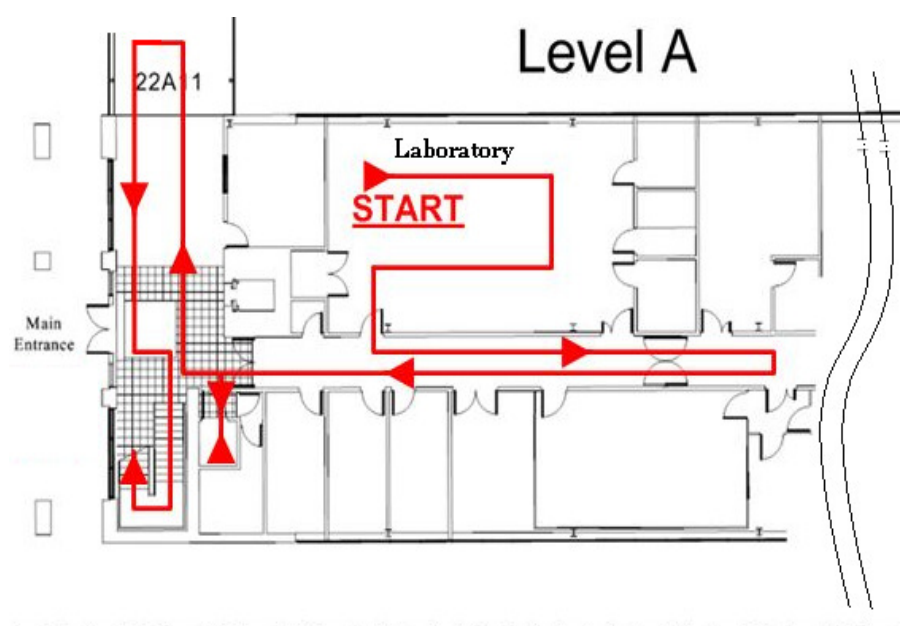

GROSS AREA

858.91sq.m.

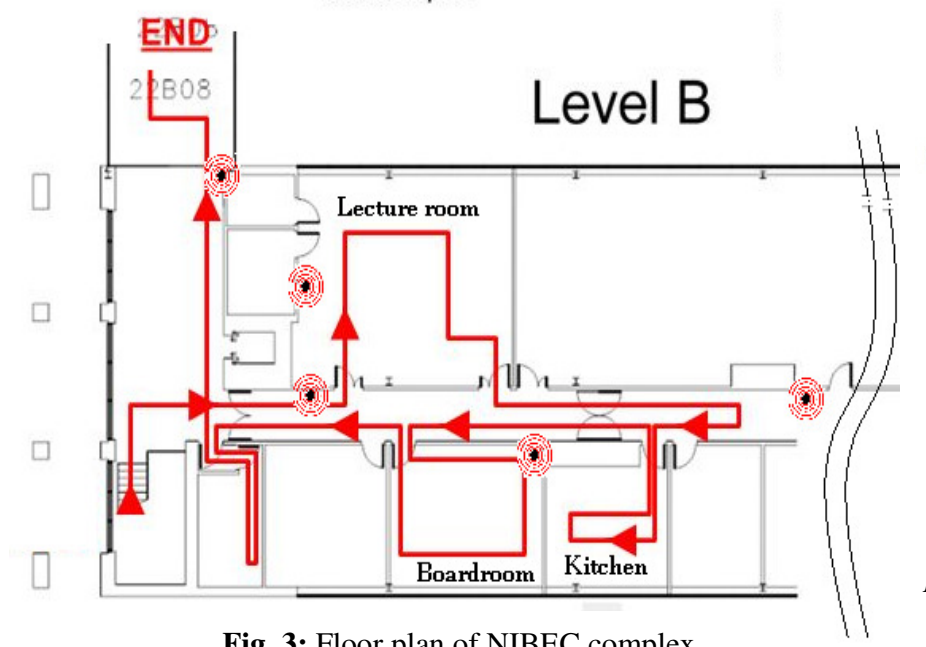

Fig. 3: Floor plan of NIBEC complex

\section{RESULTS}

\section{A. Two adjacent rooms on the same level}

This test was conducted to classify the precision of the system to locate between two adjacent rooms. The kitchen and the boardroom were chosen for the evaluation. Both were located in the second floor of NIBEC. In each of the two rooms 100 position determinations were recorded. The mobile device was arbitrarily moved within the respective rooms and the orientation of the user was constantly changed. It is noted that before the testing commenced, comparison between direct line-of-sight versus non-line-of-sight (due to body shadowing alone) revealed increased fading of the signal in the magnitude of $18 \mathrm{~dB}$. This is because signal absorption by the body, as reported by [12].

The results of accuracy are displayed in figure 4 and 5 . In case of the determined positions in the kitchen, $96 \%$ of the positions were correct. The remaining $4 \%$ were located in the corridor just outside the kitchen. In case of the measurements in the Boardroom, $87 \%$ of the positions were correct. The remaining $13 \%$ were also very close to the boardroom, located in the corridor just outside. These results demonstrate that such a positioning system is capable to determine a position within one level on a room-by-room basis.

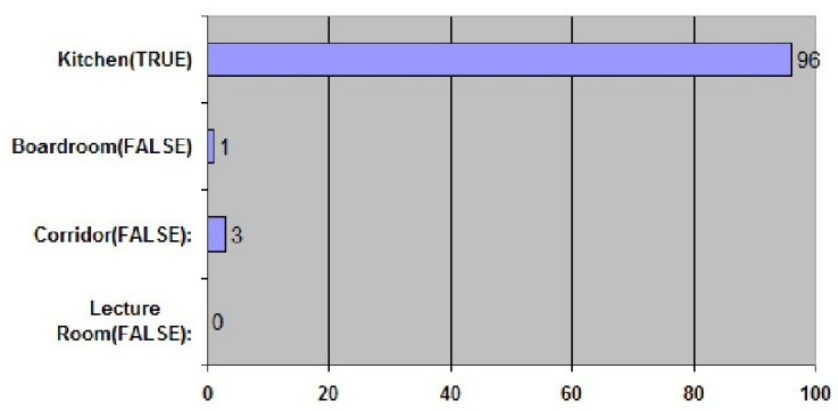

Fig. 4: 100 position estimations within the Kitchen

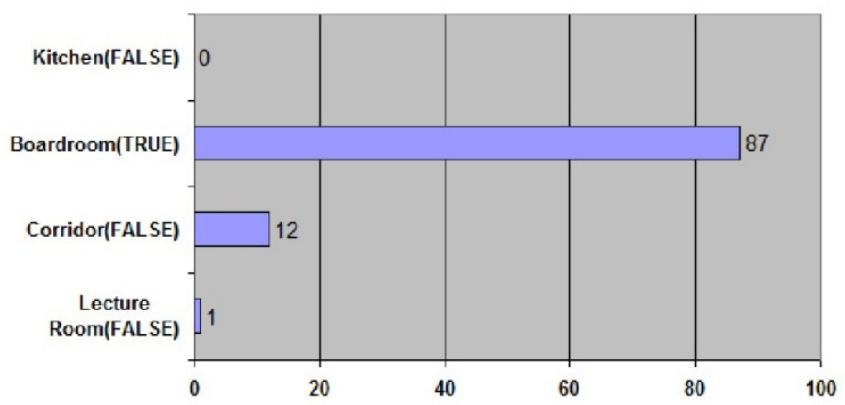

Fig. 5: 100 position estimations within the Boardroom

\section{B. Two adjacent rooms on different levels}

The lecture room on the second floor is located above the laboratory in the first floor. Both rooms have approximately the same size. Again, 100 position determinations were recorded in each room. The mobile device was arbitrarily moved within the respective rooms and the orientation of the wearer was constantly changing.

Results in figure 6 and 7 show that in the lecture room, $86 \%$ of the positions were correct. The remaining $14 \%$ were located just outside the door of the lecture room. For the laboratory, $93 \%$ of the positions were correct. The remaining $7 \%$ were also very close to the laboratory. These results demonstrate that the positioning system is also capable of distinguishing between different floor levels. 


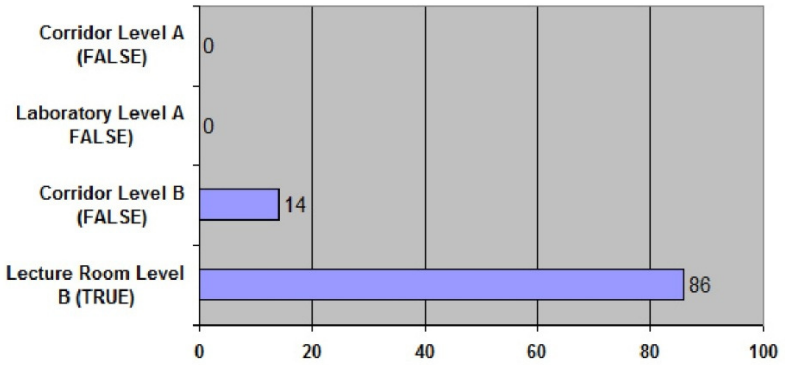

Fig. 6: 100 position estimations within the lecture room (Level B)

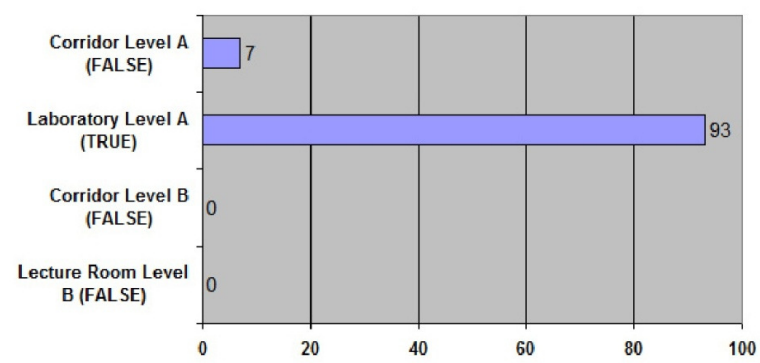

Fig: 7. 100 position estimations within the laboratory (Level A)

\section{Measurement at Fixed Locations}

In each of the four locations, RSSI information was collected in 300 trials. The performance metric used in these experiments is the error distance; the Euclidean distance between the actual position of the mobile device and its estimated location, with the actual position being measured using building blueprints. The cumulative error distribution in figure 8 shows that most of the errors occur at a distance less than $2 \mathrm{~m}$. RSSI signals were found to be Gaussian distributed. It can be also seen that the proposed indoor localisation system can achieve a resolution of $4 \mathrm{~m}$ with a probability of more than $88 \%$. This is adequate performance in comparison to commercial solutions like the Ekahau system [13].

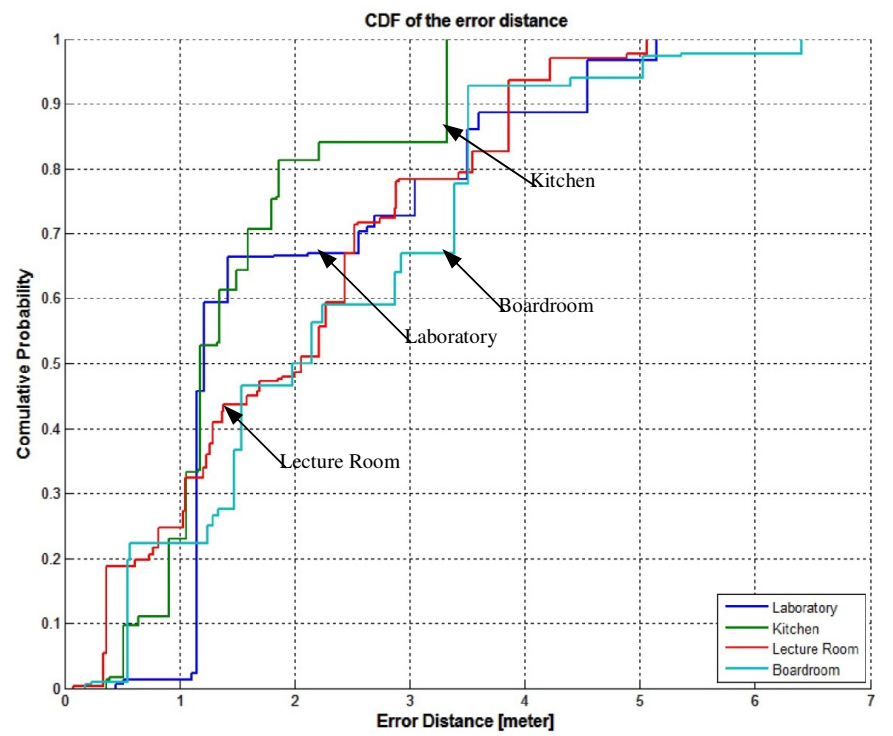

Fig: 8. Cumulative error distribution for the four locations
Accuracy has been achieved in the range of 1 to 4 meters with at least $88 \%$ precision and the system was able to detect the floor level and the room in which the person was located. Received power for all the tests ranged from $-35.2 \mathrm{dBm}$ to $81.5 \mathrm{dBm}$ with no loss of AP signal at any position.

\section{CONCLUSIONS}

In this paper, results of a wearable ambulatory patient monitoring device with commercially viable integrated Wi-Fi positioning has been presented. In the case of two rooms on the same level, the result was quite acceptable with at least $87 \%$ of correct estimations whereas the wrong estimations were just in front of the room. In case of two rooms located above each other, at least $86 \%$ of the positions were correct whereas the other remaining wrong positions were also very close to the tested room. Fixed location measurements using 300 position estimations revealed that at least $50 \%$ of the estimations were within $2 \mathrm{~m}$ and at least $88 \%$ within $4 \mathrm{~m}$ which is comparable to other purpose-built commercial solutions.

These set of presented tests show that this minimal cost retro-fitted system is able to, at least, determine the room and the floor without any additional costs if the building is sufficiently equipped with a Wi-Fi infrastructure, and demonstrates a typical accuracy of $2 \mathrm{~m}$. This system can track a mobile user in real time and offers an attractive wireless solution to a medical system which promises rapid response in emergency situations, with life-saving potential. It is considered that precision of this system can be increased by development of a larger radio map for a given environment.

Future work may focus on the development of a Smartphone graphical user interface to allow the attending doctor to locate patients without requiring locality to the central nursing monitor station. Also, testing with varying layouts and numbers of access points and for a greater number of floor levels will be of interest to fully trial the system.

\section{REFERENCES}

[1] P.A. Catherwood \& W.G. Scanlon, 'Off-body UWB channel characterisation within a hospital ward environment,' Intl. J. UWB Comms \& Systems, Vol. 1, 4, pp. 263-272, 2010.

[2] Global Markets Direct, 'Global Patient Monitoring Market Analysis \& Forecasts to 2015', Published: Jan 2009.

[3] Draeger Infinity M300 [Online]: http://www.draeger.com

[4] Welch-Allyn Micropaq [Online]: http://www.welchallyn.com

[5] D.E. Bloom, D. Canning, G. Fink, 'Program on the global demography of aging', Harvard University. Oct. 2009.

[6] RFID tracking chips [Online]: http://www.digitalangel.com

[7] GSM people location devices [Online]: http://www.teltonika.lt

[8] GPS personal tracker [Online]: http://www.universaltrackers.com

[9] J. D. Parsons, The Mobile Radio Propagation Channel. Pentech, London, 1992 (pg. 194).

[10] F. Lassabe et al, Indoor Wi-Fi positioning: techniques and systems. Annals of Telecomms '09. Vol.64, No.9-10, pgs.651-664.

[11] M.N. Borenovi et al. Positioning in WLAN environment by use of artificial neural networks and space partitioning. Annals of Telecomms, Vol. 64, No. 9-10, pgs. 665-676, October 2009.

[12] K.I. Ziri-Castro, W.G. Scanlon, N.E. Evans, 'Channel modelling and prop. measurements for a bodyworn $5.2 \mathrm{GHz}$ terminal moving in the indoor env.', IEE 12th Intl Conf Ant and Prop, vol.1, 2003, pp. 67-70.

[13] Ekahau Wi-Fi Location System [Online]: http://www.ekahau.com 